\title{
Erratum to: Ecosystem health evaluation of agricultural reservoirs using multi-metric lentic ecosystem health assessment (LEHA) model
}

Jeong-Ho Han · Bomchul Kim • Chulgoo Kim •

Kwang-Guk An

Published online: 6 January 2015

(c) The International Society of Paddy and Water Environment Engineering and Springer Japan 2015

Erratum to: Paddy Water Environ (2014)

12(Supp. 1):S7-S18

DOI 10.1007/s10333-014-0444-0

The original article has been published incorrectly with an error in the affiliation. The correct version is given in this erratum.

The online version of the original article can be found under doi:10.1007/s10333-014-0444-0.

J.-H. Han $(\bowtie) \cdot$ K.-G. An

Department of Biology, College of Biological Sciences and

Biotechnology, Chungnam National University,

Daejeon 305-764, South Korea

e-mail: yhorisa@daum.net

K.-G. An

e-mail:kgan@cnu.ac.kr

B. Kim

Center for Aquatic Ecosystem Restoration, Korea Environmental

Industry and Technology Institute, Kangwon National

University, Chuncheon, Kangwon-do 200-701, South Korea

C. Kim

Department of Environmental Science, Kangwon National

University, Chuncheon 200-701, South Korea 